\title{
Bioinformatics and 3D Printing in Radiology Research: An Answer to Our Prayers
}

\author{
Susie Medeiros Oliveira*, Sergio Augusto Lopes De Souza and Lidia Vasconcellos De Sá \\ Biomedical radiologist, Clementino Fraga Filho University Hospital, Brazil \\ Received: 制 September 03, 2018; Published: 笽 September 10, 2018 \\ *Corresponding author: Susie Medeiros Oliveira, Biomedical radiologist, Clementino Fraga Filho University Hospital, Brazil
}

\section{Opinion}

Since 1906, there has been an attempt to find tissue substitute materials to study the dosimetric effects within and around irradiated tissues. Anthropomorphic phantoms have been built in experimental radiation dosimetry. During the 1920's, water and wax were used as muscle and soft-tissue substitutes. In 1930 it was reported that the attenuation coefficients of wax differed widely from those of muscle and soft tissues. Then, wood-based phantoms were built and used for many years, but they were followed by reports saying that the wood had a variable photon attenuation property and for that, it shouldn't be used as tissue substitute either. In the 40's and 50's, researchers started a greater awareness of the importance of realism in phantom body design. So, in the early 60 's, the trend continued with the introduction of elaborate adult-sized body phantoms. They had real skeletons, body cavities, and artificial lungs, with slices that enabled the evaluation of radiation dose-distributions. From the 1970's to the present day, more phantoms have been produced for applications besides radiotherapy dosimetry such as radiodiagnosis and radiation protection in medical imaging, and for evaluating the performance of all imaging techniques like CT.

Measuring equipment and clinical techniques had become so sophisticated, that the types of tissues needing simulation and the degree of realism required between replicating materials and real tissues needed to be increased as well. Radiation physicists were no longer satisfied to use simple blocks of solid materials or tanks of liquids. They demanded composite arrays of tissue substitute substances and phantoms having increasing degrees of realism [1] However, the more complex is the tissue or organ structure, the more complex becomes its development. For instance, in the case of joints, there are no phantoms that could be used for the analysis of their entire anatomy structure. A knee joint phantom should include skin, muscles and ligaments, bones, articular cartilage, synovial membrane, synovial liquid, fibrous capsule, among others, all built with tissue-equivalent materials. This degree of realism would provide more accurate data in dosimetric studies of conditions such as chronic synovitis [1]. With the advancement of
3D technologies, new phantoms have been built using 3D medical imaging, for instance: MRI-Derived 3D-Printed Breast Phantom. It is divided into adipose tissue (printed in plastic) and fibroglandular tissues (empty parts filled with liquids) [2]. Also, the 3D printer generated thorax phantom based on CT images, with a tumour for radiation dosimetry. It was also developed with plastic and filled with tissue substitute materials [3].

The printers commercially available nowadays do not have a wide variety of materials (with different densities and compositions). Therefore, it is only possible to build anatomical phantoms for structural images, non-functional, which does not reveal physiological activities on the tissue or organ. With the limited choices of available plastics to use on 3D printers, it could be employed Hounsfield Units (HU) to select the closest material as an equivalent tissue one. Using a Software such as Invesalius is good to test different types of 3D printing materials since it segments the image by the HU range for each type of tissue. For instance, our research group has been studying materials to build a knee for dosimetric simulations. We have found the ideal material to simulate the muscle by making a CT scan of various materials that had the same density as the muscles [4]. We used invesalius 3.1 to check the HU of these materials and select the one that we were going to use to print the muscles from the knee joint (Figure 1). Since bioinformatics has allowed scientists to print tissues and organs to replace them in actual human beings, so why not use it to simulate one? The scientific community has waited more than 100 years to finally have their prayers answered when it comes to tissue substitutes, to the point where we can image a person and then print parts of this person. More and more realistic simulations are being made as well, with physical and computational phantoms using Monte Carlo codes, which validate each other. The main idea of this paper was to elicit that the advancement of this technology requires contributions from the entire scientific society to develop more realistic, flexible, cost-effective phantoms to be used in the medical routine for diagnostic imaging and treatment planning in Radiology as well. 




Figure 1: Analysis of the material to build the gastrocnemius muscle.

\section{References}

1. Ramos SMO, Thomas S, Berdeguez MBT, Sá LV, Souza SAL (2017) Anthropomorphic Phantoms - Potential for More Studies and Training in Radiology. Int J Radiol Radiat Ther 2(4): 00033.

2. Burfeindt MJ, Madison WI, Colgan TJ, Mays RO, Shea JD (2013) MRI Derived 3-D-Printed Breast Phantom for Microwave Breast Imaging Validation. IEEE Antennas Wirel Propag Lett 11: 1610-1613.

\section{ISSN: 2574-1241}

DOI: 10.26717/BJSTR.2018.08.001712

Susie Medeiros Oliveira. Biomed J Sci \& Tech Res



Submission Link: https://biomedres.us/submit-manuscript.php
3. Mayer R, Liacouras P, Thomas A, Kang M, Lin L, et al. (2015) 3D printer generated thorax phantom with mobile tumor for radiation dosimetry. Rev Sci Instrum 86(7): 074301.

4. Gear JI, Long C, Rushforth D, Chittenden SJ, Cummings C, et al. (2014) Development of patient-specific molecular imaging phantoms using a 3D printer. Med Phys 41(8): 082502.

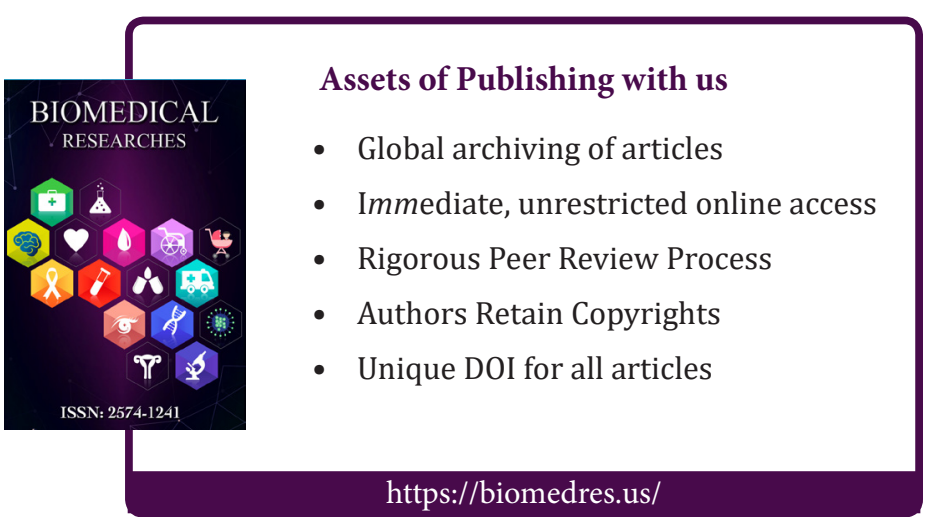

